\title{
The Impacts of Brand and Generic Advertising on Meat Demand
}

\author{
Gary W. Brester; Ted C. Schroeder
}

American Journal of Agricultural Economics, Vol. 77, No. 4. (Nov., 1995), pp. 969-979.

Stable URL:

http://links.jstor.org/sici?sici=0002-9092\%28199511\%2977\%3A4\%3C969\%3ATIOBAG\%3E2.0.CO\%3B2-F

American Journal of Agricultural Economics is currently published by American Agricultural Economics Association.

Your use of the JSTOR archive indicates your acceptance of JSTOR's Terms and Conditions of Use, available at

http://www.jstor.org/about/terms.html. JSTOR's Terms and Conditions of Use provides, in part, that unless you have obtained prior permission, you may not download an entire issue of a journal or multiple copies of articles, and you may use content in the JSTOR archive only for your personal, non-commercial use.

Please contact the publisher regarding any further use of this work. Publisher contact information may be obtained at http://www.jstor.org/journals/aaea.html.

Each copy of any part of a JSTOR transmission must contain the same copyright notice that appears on the screen or printed page of such transmission.

The JSTOR Archive is a trusted digital repository providing for long-term preservation and access to leading academic journals and scholarly literature from around the world. The Archive is supported by libraries, scholarly societies, publishers, and foundations. It is an initiative of JSTOR, a not-for-profit organization with a mission to help the scholarly community take advantage of advances in technology. For more information regarding JSTOR, please contact support@ jstor.org. 


\title{
The Impacts of Brand and Generic Advertising on Meat Demand
}

\author{
Gary W. Brester and Ted C. Schroeder
}

\begin{abstract}
The effects of meat advertising expenditures on quarterly beef, pork, and poultry demand are estimated using a nonlinear Rotterdam model. Advertising stocks are incorporated into the model as both demand shifters and price and total expenditure scaling factors. Branded beef, pork, and poultry advertising elasticities are each significantly different from zero. Generic beef and pork advertising elasticities are not significantly different from zero. Some cross-advertising elasticities are significantly different from zero. Branded beef and poultry advertising have increased total meat consumption.
\end{abstract}

Key words: brand advertising, generic advertising, meat demand, Rotterdam model.

The meat industry has spent substantial amounts of money on advertising. In 1993, combined brand and generic advertising expenditures for beef, pork, and poultry exceeded $\$ 120$ million (Leading National Advertisers). Real beef, pork, and poultry advertising expenditures increased $62 \%$ from 1980 to 1993. Despite this growth in meat advertising expenditures, little research has examined the impact of advertising on consumer demand for meat. In addition, no research has considered the cross effects of advertising among meat commodities. The objective of this study is to determine the impact of meat advertising expenditures on the demand for beef, pork, and poultry. In particular, a demand system is used to allow for cross-commodity advertising effects on competing product demand.

Estimates of the marginal impact of advertising on consumer demand are needed to assess advertising effectiveness (Wohlgenant 1993). As beef, pork, and poultry advertising expenditures increase, the potential for what Lee, Brown, and Fairchild (p. 613) labeled as a "cannibalistic impact" of advertising across these commodities increases. To what extent does meat product advertising influence overall

\footnotetext{
The authors are associate professors in the Department of Agricultural Economics at Kansas State University.

Helpful comments provided by Jim Chalfant, Tom Cox, Jim Mintert, Cynda Clary, and two anonymous reviewers are greatly appreciated. This research was supported by the Kansas Agricultural Experiment Station. Contribution No. 95-589-J of the Kansas Agricultural Experiment Station.
}

meat demand relative to merely causing substitution among meats? If meat advertising causes significant substitution among meat products, the potential gains of advertising expenditures on one meat commodity will be related to advertising expenditures on competing meats. Quantifying the impacts of direct and competing commodity advertising in the meat industry is important for firms considering brand advertising as well as producer associations considering the allocation of funds collected from checkoff programs between research and promotion activities.

Several studies have estimated impacts of advertising on various nonmeat food commodity demands (e.g., Forker and Ward; Chyc and Goddard; Kinnucan, Thompson, and Chang). Little published research has examined impacts of meat advertising on meat demand. Hoover, Hayenga, and Johnson examined the impact of generic pork advertising on consumer perceptions of pork. Intensive media advertising had mixed levels of recall and impacts depending upon the location of the promotion. The authors did not estimate the effect of advertising on pork demand.

Brooker, Eastwood, and Gray used supermarket scanner data to estimate impacts of feature advertising on ground beef, beef roast, and steak consumption for a five-store chain of supermarkets in the southeastern United States. They concluded that feature advertising had positive, significant impacts on demand with own-advertising elasticities ranging from 0.06 
for steak to 0.77 for roast. They also found a significant negative cross-advertising elasticity of -0.05 for roast advertising on ground beef consumption. Their study did not examine advertising effects between beef and competing meat products.

Jensen and Schroeter considered the effect of a specific generic beef television advertising campaign on fresh beef consumption. Their data consisted of "split-cable" panel scanner observations for 1,782 households between 1985 and 1987 in Grand Junction, Colorado. They concluded that this particular advertising campaign did not increase fresh beef consumption, and may have caused consumption to decrease.

Ward and Lambert used a single-equation, inverse demand model with beef checkoff expenditures included as one of the explanatory variables to estimate the impact of the checkoff program on beef demand. They concluded the beef checkoff program provided a $\$ 5.714$ return to producers for each $\$ 1$ invested. Three aspects of their study deserve further consideration. First, estimating a system of demand equations for competing meat commodities rather than a single equation is more compatible with demand theory. Approximate demand systems (e.g., Rotterdam model, Almost Ideal Demand System) have been used extensively to model meat demand. Such systems allow for the imposition of cross-equation restrictions implied by consumer choice theory and may be useful for evaluating advertising effects. Second, Ward and Lambert did not consider cross effects of advertising expenditures on beef substitutes. Lee, Brown, and Fairchild concluded that failure to incorporate the impact of advertising on closely related goods can lead to unreliable estimates of advertising effects. Omission of relevant variables potentially biases parameter estimates. Third, their study used beef checkoff receipts as a proxy for advertising expenditures. This proxy ignores brand and other generic advertising expenditures. The impact of these other sources of advertising should be accounted for when evaluating the marginal effectiveness of advertising.

This study uses quarterly data from 1970 through 1993 to estimate the U.S. demand for beef, pork, and poultry. Advertising expenditures are incorporated into a Rotterdam model to evaluate the impact of brand and generic advertising on the demand for these commodities. Attention is given to whether meat advertising increases overall meat consumption and the extent to which meat product advertising leads to substitution among competing meats.

\section{Incorporating Advertising into the Rotterdam Model}

A system of meat demand equations is estimated using the absolute price version of the Rotterdam model (Theil). The Rotterdam model is based on consumer demand theory; it is linear in parameters and as flexible a functional form as the translog, miniflex Laurent, and Almost Ideal Demand System models (Mountain). The system consists of demand equations for beef, pork, poultry, and other (food and nonfood) consumption items. ${ }^{1}$ The model assumes that meat products are Hicksian separable from other food and nonfood consumption items (Varian, p. 147). The inclusion of an equation representing other consumption items (and the use of per capita total personal consumption expenditures as the income variable) implies that estimates of unconditional elasticities are derived from the model. ${ }^{2}$

Several approaches can be used to augment demand models to include advertising effects depending upon the assumed interaction of advertising on the demand for food products. For example, if one assumes advertising is only a demand shifter, advertising expenditures can be incorporated into demand functions as shift variables. Such an approach has been commonly used for examining advertising effects on nonmeat food commodities (e.g., Kaiser et al.; Ward and Dixon; Wohlgenant and Clary). Another approach is to assume that advertising affects demand elasticities. Such effects would occur if advertising creates product differentiation through persuasion or if advertising provides information to consumers. In either case, one can think of advertising as scaling (or adjusting) prices and total expenditure. Essentially, scaling introduces indirect price effects generated by advertising expenditures. The scaling hypothesis has been incorporated into several types of demand models (e.g., Duffy; Goddard and Cozzarin; Green, Carman, and

LaFrance and Hanemann noted that incomplete demand sys tems are weakly integrable if such systems are augmented with an artificial composite commodity representing "other goods."

${ }^{2}$ If meats are weakly separable from other consumption items, a conditional demand system could be estimated. In this case, the expenditure variable would consist of per capita meat expenditures. However, LaFrance noted that unless one imposes severe restrictions on the model, the meat expenditures variable in a conditional demand system cannot be weakly exogenous. Thus, SUR parameter estimates will be inconsistent. The problem is likely avoided by estimating an unconditional demand system which uses per capita total personal consumption expenditures as the expenditure variable. That is, total consumption expenditures are likely to be exogenous with the consumption of individual meat products. 
McManus). Translating represents a third approach to incorporating advertising into demand models. In this case, fixed costs that are functions of advertising are included in demand functions. These fixed costs are interpreted as psychological needs or subsistence requirements of products generated by advertising. Pollak and Wales $(1980,1981)$ used translating to incorporate demographic factors into demand functions. Green used translating to incorporate advertising expenditures into an Almost Ideal Demand System. Cox considered both translating and scaling effects of advertising on the $\mathrm{Ca}$ nadian demand for fats and oils within a Rotterdam model. Translating was marginally rejected but scaling was not rejected.

Presumably, brand and generic advertising campaigns are designed to increase the consumption of meat products (through either persuasion or by providing information) rather than to instill a psychological need or subsistence requirement for these products. Therefore, Brown and Lee's Rotterdam model specification, in which advertising expenditures serve a dual role of scaling prices and total expenditures and as a shifter of demand, is appropriate. Brown and Lee's specification assumes that only own-advertising expenditures affect the demand for a product (i.e., no cross-advertising effects). The specification used here is more general in that cross-advertising effects are considered. An estimable, nonlinear, log differential form of the Rotterdam model for each discrete time period $t$ (unless explicitly required, time subscripts have been suppressed) for each of $n$ demand equations with advertising effects included in the system is given by

$$
\begin{aligned}
& \text { (1) } \bar{w}_{i} \Delta \ln Q_{i} \\
& =\beta_{i}\left\{\Delta \ln X-\sum_{j=1}^{J} \bar{w}_{j}\left[\Delta \ln P_{j}-\left(\sum_{k=1}^{K} R_{j k} \Delta \ln A_{k}\right)\right]\right\} \\
& +\left\{\sum_{j=1}^{J} \gamma_{i j}\left[\Delta \ln P_{j}-\left(\sum_{k=1}^{K} R_{j k} \Delta \ln A_{k}\right)\right]\right\} \\
& -\left\{\sum_{k=1}^{K} R_{i k} \bar{w}_{i} \Delta \ln A_{k}\right\}+\left\{\sum_{s=1}^{S} \delta_{i s} \Delta D_{s}\right\}+U_{i} \\
& i=1,2, \ldots, n
\end{aligned}
$$

where $\bar{w}_{i t}=1 / 2\left(w_{i t}+w_{i t-1}\right)$, and $w_{i}$ is the expenditure share weight of the $i$ th product, $\Delta$ is the first difference operator, $P_{j}$ is the retail price of each meat commodity and an aggregate commodity representing other consumption items, $Q_{i}$ is per capita constant dollar expenditures on each meat commodity and other consumption items, $X$ is per capita total personal consumption expenditures, $A_{k}$ is a measure of the stock of the $k$ th type of advertising, $D_{s}$ is a seasonal (quarterly) dummy variable, $U_{i}$ is a temporally independent error term that is contemporaneously correlated across the $n$ equations, and the $\beta_{i}$ 's, $R_{j k}$ 's, $\gamma_{i j}$ 's, and $\delta_{i s}$ 's are parameters. ${ }^{3}$ The $R_{j k}$ parameters represent the elasticity of the $j$ th scaling effect with respect to the $k$ th type of advertising expenditure in each equation.

The nontestable restrictions in equation (2) impose adding up, and the testable restrictions in equation (3) impose homogeneity and symmetry across the demand system:

$$
\begin{array}{ll}
\text { Adding up: } & \sum_{i=1}^{n} \beta_{i}=1 ; \\
\sum_{i=1}^{n} \gamma_{i j}=0, & j=1,2, \ldots, J ; \\
\sum_{i=1}^{n} R_{i k} \bar{w}_{i}=0, & k=1,2, \ldots, K ; \\
\sum_{i=1}^{n} \delta_{i s}=0, & s=2,3,4
\end{array}
$$

(3) Homogeneity: $\sum_{j=1}^{J} \gamma_{i j}=0$;

Symmetry: $\gamma_{i j}=\gamma_{j i}$.

The adding-up conditions result in a singular residual variance/covariance matrix. However,

\footnotetext{
${ }^{3}$ The Rotterdam model can be estimated using either quantities or constant dollar expenditures as dependent variables. Christensen and Manser used constant dollar expenditures to aggregate component meat types. Constant dollar expenditures are used here to facilitate the calculation of expenditure share weights as the price data are indices. Constant dollar expenditures are calculated by multiplying quantity data by 1983 retail prices (i.e., $\$ 2.318 / \mathrm{lb}$ for beef, $\$ 1.623 / \mathrm{lb}$ for pork, and $\$ 0.728 / \mathrm{lb}$ for broiler prices which is used as a proxy for poultry prices).
} 


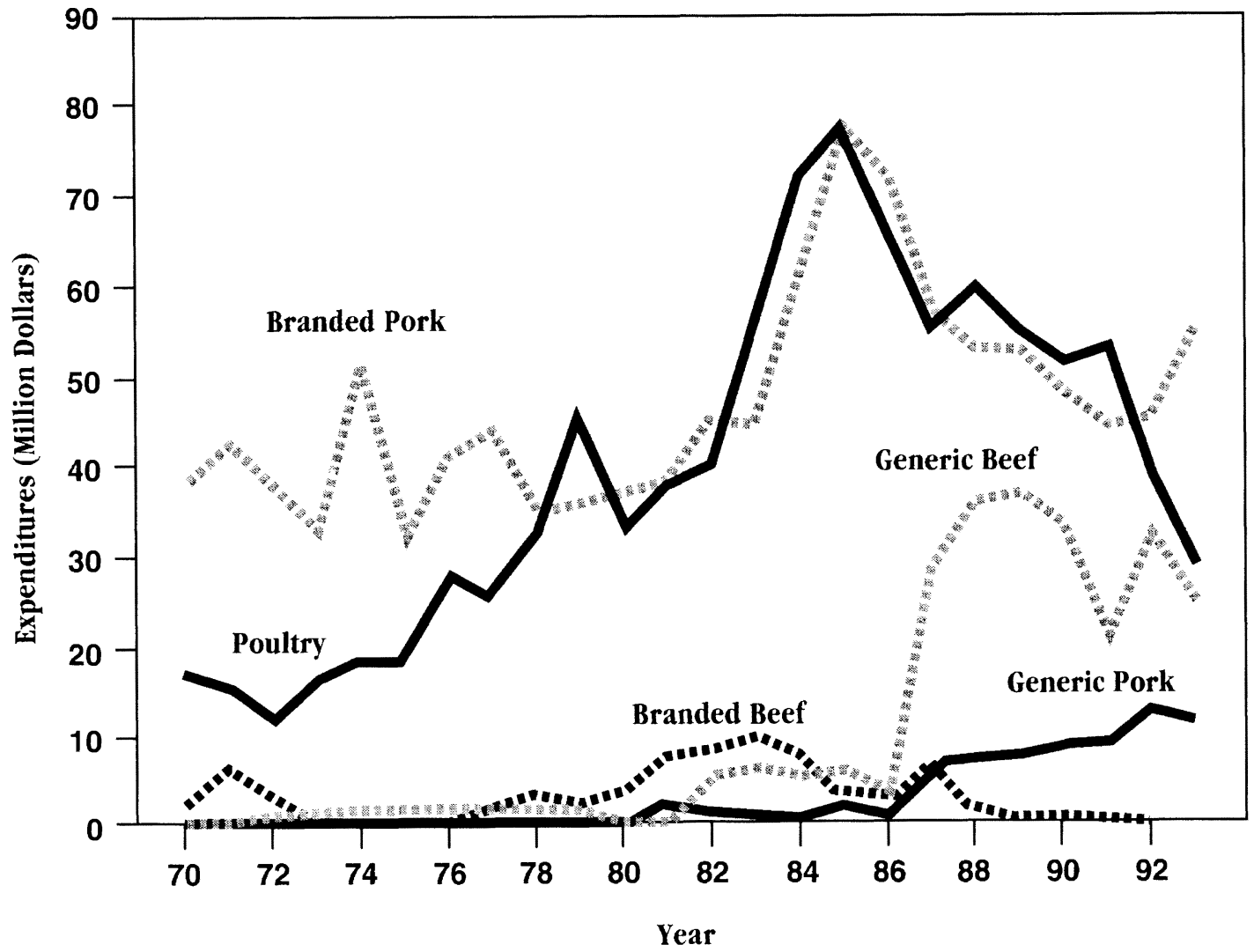

Figure 1. Real annual beef, pork, and poultry advertising expenditures (1993 dollars), 1970-93

this matrix must be inverted in the SUR estimation procedure. Thus, one of the $n$ equations must be deleted from the system for purposes of estimation. ${ }^{4}$ However, equations (2) and (3) can be used to recover the parameters of the deleted equation.

\section{Data}

Beef, pork, and poultry (including turkey) per capita consumption data were obtained from the U.S. Department of Agriculture's Livestock and Meat Situation and Outlook Report. Monthly price indices for these commodities

\footnotetext{
${ }^{4}$ In some software programs, the calculated variance/covariance matrix may be only nearly singular. Thus, one can sometimes obtain parameter estimates even when all $n$ equations are included in the estimation procedure. Nonetheless, if all adding-up restrictions are imposed across the $n$ equations, the system is overidentified which results in nonunique parameter "estimates." Consequently, one equation must always be deleted for purposes of estimation.
}

and the consumer price index for nondurable goods were taken from CPI Detailed Reports (U.S. Department of Labor). ${ }^{5}$ The value of each price index for the middle month of each quarter was used as the quarterly observation. Total personal consumption expenditures and population were collected from the Survey of Current Business (U.S. Department of Commerce). Advertising expenditures were collected from Class/Brand QTR \$ published by Leading National Advertisers. Beef advertising was separated into generic and branded product adver-

\footnotetext{
5 The price of "other consumption goods" is obtained from the CPI, per capita total personal consumption expenditures (deflated by the personal consumption expenditure implicit price deflator), constant dollar expenditures, and price indexes for beef, pork, and poultry. Deflated per capita personal consumption expenditures and constant dollar expenditures on beef, pork, and poultry are used to calculate expenditure share weights $\left(s_{t}\right)$ for the four goods. The CPI is known and is represented by $C P I_{t}=\sum_{t=1}^{4} s_{t t} P_{t t}$ where $P$ is the price index for the $i$ th good. The price index of "other consumption goods" (say $P_{4}$ ) is the only unknown value in the equation. Therefore, solving for $P_{4}$ results in the price index of "other consumption goods" (Wohlgenant 1989, p. 172).
} 
tising. Pork advertising was separated into generic and branded product advertising. Poultry advertising was all branded and included advertising expenditures on both chicken and turkey. ${ }^{6}$ Food service advertising expenditures were not considered in this study.

Figure 1 illustrates trends in real (deflated by the personal consumption expenditures implicit price deflator) annual advertising expenditures for brand and generic beef and pork and for poultry from 1970 through 1993 . Real advertising has increased considerably for each of these products. Total beef advertising was quite small relative to pork and poultry until 1986 when the Beef Industry Council began generic advertising. Branded beef advertising remains small relative to other goods. Between 1980 and 1993, total real beef advertising increased more than $350 \%$, total pork increased $84 \%$, poultry declined $12 \%$, and combined advertising increased $62 \%$.

\section{Empirical Results}

Prior to estimating the demand system, the data were evaluated using a nonparametric test of the Generalized Axiom of Revealed Preference (GARP). Alston and Chalfant suggested using a nonparametric test of revealed preference as a pretest for changes in tastes and preferences prior to demand analysis. Violations of GARP indicate that observed behavior cannot be rationalized by a utility function based solely upon prices and expenditures. The power of such tests can be improved by adjusting consumption data for changes in real expenditures. Therefore, consumption data were adjusted for changing real expenditures following Chalfant

\footnotetext{
${ }^{6}$ Only advertising expenditures that were identified with a particular beef, pork, or poultry product were included. Advertising for game, seafood, miscellaneous meats, lamb, and nonproduct specific lunch meats and hotdogs were excluded. Nine quarterly observations for generic pork advertising and four observations for branded beef were zero. Because logarithmic transformations are required in the Rotterdam model, zero observations were replaced with a small positive number $(\$ 100)$. To test the sensitivity of results to the choice of "small positive numbers," we reestimated the model using different scalar additions $(\$ 1, \$ 1,000$, and $\$ 10,000)$ and compared the results to our original ad hoc choice of $\$ 100$. The results using $\$ 1$ and $\$ 1,000$ as "small positive numbers" were practically identical to those obtained using $\$ 100$. However, elasticity estimates showed minor changes when we used $\$ 10,000$. Thus, results are invariant to scalar selections that are relatively close to zero. In addition, we reestimated the model after adding $\$ 100$ to all advertising (i.e., both zero and nonzero) observations. The results were, for all practical purposes, identical to those obtained by adding $\$ 100$ to only the zero advertising observations. The results were also invariant to adding $\$ 1$ and $\$ 1,000$ to all advertising observations.
}

and Alston. Nineteen violations out of 4,560 comparisons were found. The largest violation was $0.95 \%$ of real total meat expenditures for the quarter in which it occurred. Most violations were much smaller (the nineteen violations averaged only $0.31 \%$ of real total meat expenditures). Thus, it does not appear that the period (1970-93) was dominated by changing tastes and preferences (i.e., the type of change one would expect to find if advertising affected consumption behavior). However, the power of such tests may not be sufficient to find such violations. In addition, the choice of income elasticity (unity) used to adjust the data for changing real expenditures may be inadequate. Finally, modeling a "representative" consumer (i.e., using market data adjusted to a per capita basis) rather than an actual consumer along with other aggregation issues may mask changes in tastes and preferences which may occur as a result of advertising.

The Rotterdam model [equation (1)] was estimated using nonlinear seemingly unrelated regressions in TSP 4.2. ${ }^{7}$ The equation representing consumption of other goods was deleted from the estimation procedure. Symmetry, homogeneity, and adding up were imposed. ${ }^{8}$ Firstdifferenced quarterly dummy variables were included to account for seasonality in consumption. The parameters of the deleted equation were recovered using the adding-up restrictions presented in equation (2). Because the parameters of the deleted equation are linear combinations of random variables, their standard errors are easily calculated.

Advertising stock variables were estimated as functions of contemporaneous and lagged advertising expenditures. The theoretical rationale for considering the dynamic nature of the relationship between demand and advertising expenditures has a long history (e.g., Nerlove and Waugh; Sasuly; Waugh). Empirical findings

\footnotetext{
${ }^{7}$ Wu-Hausman tests for the exogeneity of product prices were performed for each equation using lagged own-prices, lagged carcass-weight beef, pork, and poultry production, income, advertising expenditures, and quarterly dummy variables as instruments. The null hypothesis that prices were exogenous could not be rejected.

${ }^{8}$ Technically, in most demand systems, adding up is not imposed as a parametric restriction because one of the equations must be deleted for estimation purposes. The restriction is actually imposed when the parameter estimates for the deleted equation are calculated. Of course, if the estimated parameters are invariant to the choice of equation that is deleted (as is the case with iterated nonlinear seemingly unrelated regressions), the adding-up condition is essentially "imposed." However, in the Rotterdam model, which incorporates scaling, the adding-up restrictions on the scaling elasticities $\left(R_{j k}\right)$ must be imposed parametrically because each $R_{j k}$ (even those for the deleted equation) appears within each equation.
} 
Table 1. Definitions of Variables

\begin{tabular}{|c|c|}
\hline Variable & Definition \\
\hline \multicolumn{2}{|l|}{ Dependent } \\
\hline$Q B E E F$ & $\begin{array}{l}\text { Expenditure share weighted first differences of the natural logarithm of per capita constant } \\
\text { dollar expenditures }(1983=\$ 2.318 \text { per pound }) \text { on beef }\end{array}$ \\
\hline$Q P O R K$ & $\begin{array}{l}\text { Expenditure share weighted first differences of the natural logarithm of per capita constant } \\
\text { dollar expenditures }(1983=\$ 1.623 \text { per pound) on pork }\end{array}$ \\
\hline$Q P O U L T$ & $\begin{array}{l}\text { Expenditure share weighted first differences of the natural logarithm of per capita constant } \\
\text { dollar expenditures }(1983=\$ 0.728 \text { per pound }) \text { on poultry }\end{array}$ \\
\hline QOTHER & $\begin{array}{l}\text { Expenditure share weighted first differences of the natural logarithm of per capita constant } \\
\text { dollar expenditures on other consumption goods }\end{array}$ \\
\hline \multicolumn{2}{|l|}{ Independent } \\
\hline INCOME & $\begin{array}{l}\text { The difference between first differences of the natural logarithm of per capita personal } \\
\text { consumption expenditures and a Divisia price index }\end{array}$ \\
\hline$P B E E F$ & First differences of the natural logarithm of the price index of beef, $1983=100$ \\
\hline PPORK & First differences of the natural logarithm of the price index of pork, $1983=100$ \\
\hline PPOULT & First differences of the natural logarithm of the price index of poultry, $1983=100$ \\
\hline POTHER & $\begin{array}{l}\text { First differences of the natural logarithm of the price index of other consumption goods, } \\
1983=100\end{array}$ \\
\hline$B R D B F A$ & Stock of branded beef advertising $(\$ 1,000)$ deflated by a Divisia price index \\
\hline GENBFA & Stock of generic beef advertising $(\$ 1,000)$ deflated by a Divisia price index \\
\hline$B R D P K A$ & Stock of branded pork advertising $(\$ 1,000)$ deflated by a Divisia price index \\
\hline GENPKA & Stock of generic pork advertising $(\$ 1,000)$ deflated by a Divisia price index \\
\hline$P Y A$ & Stock of poultry advertising $(\$ 1,000)$ deflated by a Divisia price index \\
\hline DFDUM2 & First differences of a dummy variable for the second quarter of each year \\
\hline DFDUM3 & First differences of a dummy variable for the third quarter of each year \\
\hline DFDUM4 & First differences of a dummy variable for the fourth quarter of each year \\
\hline
\end{tabular}

from many advertising studies support the hypothesis that advertising has carryover (lagged) effects (e.g., Cox; Jensen and Schroeter; Ward and Dixon; Wohlgenant and Clary). Unfortunately, theory provides little information as to the structure and length of these dynamic processes. Thus, most researchers resort to specifying a lag structure (usually a low-order linear or polynomial function) and allowing the data to choose the optimal number of lags to include in the specification of an advertising stock variable. Following a procedure suggested by Cox, a second-order exponential lag specification was used to represent the advertising stock variables. This specification is relatively flexible in that it can represent either geometric or polynomial lag structures. In addition, if one uses the usual endpoint restrictions, the specification is quite parsimonious. Assuming lagged effects do not extend beyond one year, the second-order exponential function has the form

$$
A_{k}=\sum_{j=0}^{4} W_{k, t-j} a_{k, t-j}
$$

where

$$
\text { (5) } \quad W_{k, t-j}=\left[\exp \left(Z_{0 k}+Z_{1 k} j+Z_{2 k} j^{2}\right)\right]
$$

and $a_{k}$ represents nominal advertising expenditures (in levels) and $Z_{i k}$ are parameters. Using endpoint restrictions, the weight of the last lag $(j=4)$ is set equal to zero and the weight on contemporaneous expenditures $(j=0)$ is set equal to 1 . The latter restriction represents a normalization that sets the scale of measurement for the advertising stock variables. Using the endpoint restrictions results in the addition of only a single parameter for each $k$ th type of advertising. To illustrate, note equation (5) reduces to

\section{(6) $\quad Z_{0 k}=0$}

when $j=0$ because $W_{k, t-j}$ equals 1 and $\exp (0)=$ 1 . In addition, given that $W_{k, t-j}$ equals zero when $j=4$ and noting that $\exp (-20) \approx 0$, equation (5) can be expressed as

$$
Z_{1 k}=-5.0-4 Z_{2 k} \text {. }
$$

Substituting equations (6) and (7) into equation (5) yields 


$$
W_{k, t-j}=\left[\exp \left(-5.0 j+Z_{2 k}\left(j^{2}-4 j\right)\right] .\right.
$$

Equation (8) can be substituted into equation (4) to obtain a measure of advertising stocks in levels. However, the Rotterdam model is estimated in log differential form. Thus, taking first differences of the natural logarithm of equation (4) yields

$$
\Delta \ln A_{k}=\ln \left(\sum_{j=0}^{4} W_{k, t-j} a_{k, t-j}\right)-\ln \left(\sum_{j=0}^{4} W_{k, t-j} a_{k, t-j-1}\right) .
$$

The first difference of the natural logarithm of advertising stocks [the left-hand side of equation (9)] is in nominal terms. To obtain a real measure, equation (9) is deflated by a firstdifferenced Divisia price index of the form

$$
\Delta \ln P^{*}=\sum_{j=1}^{n} \bar{w}_{j} \Delta \ln P_{j}
$$

After substituting equation (8) into equation (9) and subtracting equation (10), the resulting function is substituted into the nonlinear Rotterdam model [equation (1)] as the final step prior to estimation.

Table 1 presents variable definitions. Initial regression results yielded estimates of the lag weighting parameters $\left(Z_{2 k}\right)$ for branded beef, pork, and poultry advertising that were not significantly different from zero. In addition, branded pork and poultry advertising tended to be collinear when lengthy lags were considered on those two variables. Thus, the lag specification for these three advertising variables was shortened by one-quarter [which requires appropriate changes to equation (8) for these advertising variables] and the model was reestimated. However, the lagging function parameters were again insignificant, so the process was repeated. Ultimately, only contemporaneous values for the branded advertising variables were used in the model, while the original contemporaneous and three-quarter lags were maintained for generic beef and generic pork advertising variables.

Table 2 presents the final regression results. Parameter estimates were invariant to several different sets of starting values. Curvature restrictions are met in that the matrix of price effects is negative semidefinite. The own-price effects are all significantly different from zero, as are most of the cross-price effects. The cross-price effects indicate that the meat com- modities are substitutes. The income parameters are not significantly different from zero for any of the meat equations. The lag weighting coefficient for generic beef advertising is -1.96 with a $t$-value of -8.27 . The lag weighting coefficient for generic pork advertising is -2.97 with a $t$-value of -7.02 . These values indicate a polynomial (quadratic) lag structure that peaks near the end of the first quarter and approaches zero by the end of the third quarter (Cox, p. 162).

Table 2 also presents the parameter estimates of the scaling elasticities and their t-values. Recall that scaling elasticities represent the scaling effects on prices and expenditures resulting from changes in advertising expenditures. Thus, they do not represent the effects of advertising on the demand for products per se. Branded pork, generic pork, and poultry advertising scaling elasticities were significantly different from zero in the beef equation. In the pork equation, generic beef and branded pork scaling elasticities were sigifificantly different from zero. Generic pork and poultry advertising scaling elasticities were significantly different from zero in the poultry equation, whereas branded beef and poultry advertising scaling elasticities were significantly different from zero in the other goods equation. ${ }^{9}$ We performed a likelihood ratio test of the null hypothesis that all cross-advertising scaling elasticities in the system were equal to zero as a group. The null hypothesis was rejected at the 0.01 level.

\section{Estimated Elasticities}

Table 3 presents unconditional compensated price, income, and advertising elasticities. Price $\left(e_{i j}\right)$ and income $\left(e_{i}\right)$ elasticities are calculated as

$$
\begin{aligned}
& e_{i j}=\gamma_{i j} /\left[\left(\sum_{t=2}^{T} \bar{w}_{i t}\right) / T\right] \\
& e_{i}=\beta_{i} /\left[\left(\sum_{t=2}^{T} \bar{w}_{i t}\right) / T\right]
\end{aligned}
$$

\footnotetext{
9 A linear Rotterdam model which considered advertising as only demand shifters (i.e., excluding scaling effects) was also estimated. Estimates of price elasticities were very similar between the models, suggesting that scaling has negligible effects. However, a statistical test of the scaling hypothesis is not possible because the linear model is not nested within the nonlinear model (i.e., setting the scaling elasticities to zero also involves setting the demand shift effects to zero in the nonlinear model). In the interest of generality, we have chosen to report the results from the nonlinear specification.
} 
Table 2. Estimated Regression Coefficients of the Rotterdam Model

\begin{tabular}{|c|c|c|c|c|c|c|c|c|c|c|c|c|c|c|c|}
\hline \multirow{3}{*}{$\begin{array}{l}\text { Dependent } \\
\text { Variables }\end{array}$} & \multicolumn{13}{|c|}{ Independent Variables } & \multirow[b]{3}{*}{$\mathrm{R}^{2}$} & \multirow[b]{3}{*}{ DW } \\
\hline & \multirow[b]{2}{*}{ PBEEF } & \multirow[b]{2}{*}{ PPORK } & \multirow[b]{2}{*}{ PPOULT } & \multirow[b]{2}{*}{ POTHER } & \multirow[b]{2}{*}{ INCOME } & \multirow[b]{2}{*}{ DFDUM2 } & \multirow[b]{2}{*}{ DFDUM3 } & \multirow[b]{2}{*}{ DFDUM 4} & \multicolumn{5}{|c|}{ Scaling Elasticities for } & & \\
\hline & & & & & & & & & $B R D B F A$ & GENBFA & $B R D P K A$ & GENPKA & $P Y A$ & & \\
\hline \multirow[t]{2}{*}{$Q B E E F$} & -0.0115 & 0.0021 & 0.0011 & 0.0083 & 0.0028 & 0.0002 & 0.0006 & 0.00008 & -0.0135 & -0.0264 & 0.0645 & -0.0082 & -0.0366 & 0.51 & 2.40 \\
\hline & $(-7.61)$ & (3.28) & $(2.05)$ & $(4.66)$ & $(0.58)$ & $(1.26)$ & $(4.97)$ & $(0.61)$ & $(-1.52)$ & $(-1.65)$ & $(2.75)$ & $(-2.03)$ & $(-2.48)$ & & \\
\hline & & $(-12.18)$ & $(1.00)$ & $(4.90)$ & $(0.73)$ & $(-6.55)$ & $(-3.76)$ & $(8.11)$ & $(-0.73)$ & $(1.89)$ & $(-4.56)$ & (1.01) & $(1.10)$ & & \\
\hline \multirow[t]{2}{*}{ QPOULT } & & & -0.0017 & 0.0002 & -0.00002 & 0.0003 & 0.0005 & 0.0007 & 0.0033 & 0.0206 & 0.0070 & 0.0166 & -0.0601 & 0.93 & 2.15 \\
\hline & & & $(-4.02)$ & $(0.48)$ & $(-0.01)$ & (7.33) & $(11.85)$ & (18.74) & $(0.52)$ & $(1.61)$ & $(0.25)$ & (3.39) & $(-3.86)$ & & \\
\hline QOTHER & & & & -0.0125 & 0.9956 & -0.00006 & -0.0009 & -0.0013 & 0.0004 & 0.00002 & 0.0001 & 0.00003 & 0.0009 & & \\
\hline
\end{tabular}


Table 3. Estimated Unconditional Compensated Price, Income, and Advertising Elasticities

\begin{tabular}{|c|c|c|c|c|c|c|c|c|c|c|}
\hline \multirow{2}{*}{$\begin{array}{l}\text { Elasticity } \\
\text { of the } \\
\text { Dependent } \\
\text { Variables }\end{array}$} & \multicolumn{4}{|c|}{ With Respect to the Price of } & \multicolumn{6}{|c|}{ With Respect to } \\
\hline & PBEEF & PPORK & PPOULT & POTHER & INCOME & $B R D B F A$ & GENBFA & $B R D P K A$ & GENPKA & $P Y A$ \\
\hline$Q B E E F$ & $\begin{array}{c}-0.56 \\
(-7.61)\end{array}$ & $\begin{array}{c}0.10 \\
(3.28)\end{array}$ & $\begin{array}{c}0.05 \\
(2.05)\end{array}$ & $\begin{array}{c}0.41 \\
(4.66)\end{array}$ & $\begin{array}{c}0.13 \\
(0.58)\end{array}$ & $\begin{array}{c}0.007 \\
(1.87)\end{array}$ & $\begin{array}{c}0.006 \\
(0.95)\end{array}$ & $\begin{array}{c}-0.013 \\
(-1.20)\end{array}$ & $\begin{array}{c}0.002 \\
(1.27)\end{array}$ & $\begin{array}{c}0.017 \\
(2.82)\end{array}$ \\
\hline$Q P O R K$ & $\begin{array}{c}0.23 \\
(3.28)\end{array}$ & $\begin{array}{c}-0.69 \\
(-12.18)\end{array}$ & $\begin{array}{c}0.04 \\
(1.00)\end{array}$ & $\begin{array}{c}0.43 \\
(4.90)\end{array}$ & $\begin{array}{c}0.17 \\
(0.73)\end{array}$ & $\begin{array}{c}0.006 \\
(1.43)\end{array}$ & $\begin{array}{c}-0.009 \\
(-1.27)\end{array}$ & $\begin{array}{c}0.033 \\
(2.76)\end{array}$ & $\begin{array}{l}-0.0005 \\
(-0.27)\end{array}$ & $\begin{array}{c}0.004 \\
(0.57)\end{array}$ \\
\hline QPOULT & $\begin{array}{c}0.21 \\
(2.05)\end{array}$ & $\begin{array}{c}0.07 \\
(1.00)\end{array}$ & $\begin{array}{c}-0.33 \\
(-4.02)\end{array}$ & $\begin{array}{c}0.05 \\
(0.48)\end{array}$ & $\begin{array}{l}-0.003 \\
(-0.01)\end{array}$ & $\begin{array}{r}0.001 \\
(0.51)\end{array}$ & $\begin{array}{l}-0.011 \\
(-2.06)\end{array}$ & $\begin{array}{c}-0.008 \\
(-0.59)\end{array}$ & $\begin{array}{c}-0.010 \\
(-3.62)\end{array}$ & $\begin{array}{r}0.047 \\
(5.45)\end{array}$ \\
\hline QOTHER & $\begin{array}{c}0.009 \\
(4.66)\end{array}$ & $\begin{array}{c}0.004 \\
(4.90)\end{array}$ & $\begin{array}{l}0.0002 \\
(0.48)\end{array}$ & $\begin{array}{c}-0.01 \\
(-5.43)\end{array}$ & $\begin{array}{c}1.03 \\
(169.44)\end{array}$ & $\begin{array}{l}-0.0002 \\
(-2.02)\end{array}$ & $\begin{array}{l}0.00002 \\
(0.12)\end{array}$ & $\begin{array}{l}-0.00001 \\
(-0.03)\end{array}$ & $\begin{array}{l}0.00001 \\
(0.26)\end{array}$ & $\begin{array}{l}-0.0006 \\
(-3.80)\end{array}$ \\
\hline
\end{tabular}

Note: Numbers in parentheses are the t-values for the elasticity estimates. Elasticities are calculated at the means of the two-period moving average expenditure share weights: 0.0204 (beef), 0.0092 (pork), 0.0052 (poultry), and 0.9651 (other goods).

The price elasticities are comparable to those reported in previous studies (Brester and Wohlgenant; Dahlgran; Eales and Unnevehr). The income elasticities are not significantly different from zero.

Brown and Lee derive an expression for advertising elasticities for the general case where cross-advertising elasticities exist:

$$
x_{i k}=\left(-R_{i k}\right)-\left(\sum_{j=1}^{J} e_{i j} R_{j k}\right)
$$

where $x_{i k}$ is the percentage change in the demand for the $i$ th product caused by a $1 \%$ change in the level of the $k$ th advertising. Standard errors for the advertising elasticity estimates were calculated using Taylor series expansions.

In the beef equation, the branded beef advertising elasticity is significantly different from zero and indicates that a $10 \%$ increase in branded beef advertising increases beef consumption by $0.07 \%$. Generic beef advertising is not significantly different from zero. However, if one ignores the standard error of this parameter estimate for purposes of illustration, a $10 \%$ increase in generic beef advertising may increase demand by $0.06 \%$. An upper bound of the own-price flexibility of beef can be obtained by using the reciprocal of the estimated own-price elasticity. Assuming all other factors constant, the $0.06 \%$ increase in demand translates into a $0.01 \%$ increase in retail beef price. This represents an upper bound on the effect of advertising on retail price given the method used to calculate the price flexibility. Using a single-equation approach, Ward and Lambert estimated that a $10 \%$ increase in generic beef advertising resulted in a $0.05 \%$ increase in retail beef price. Thus, our estimate of the marginal impact of generic beef advertising on real retail beef price is at most one-fifth of Ward and Lambert's. Factors which may account for the difference include $(a)$ different measures of advertising expenditures, $(b)$ the use of a theoretically consistent system of demand equations, $(c)$ inclusion of competing commodity advertising expenditures, and $(d)$ different consumer demand specifications.

The only cross-advertising elasticity in the beef equation which is clearly significantly different from zero is that of poultry. However, the estimated effect is positive which is opposite the expected result.

The estimated elasticity of demand for pork with respect to branded pork advertising is positive and significant. A $10 \%$ increase in branded pork advertising increases pork consumption $0.33 \%$. Generic pork advertising is not significantly different from zero. None of the cross-advertising elasticities are significant in the pork equation.

Poultry advertising has a significant positive impact on poultry demand with a $10 \%$ increase in advertising increasing demand $0.5 \%$. Generic beef and generic pork cross-advertising effects are both significantly different from zero and their signs meet a priori expectations in the poultry equation.

Branded beef and poultry advertising have a significantly negative effect on consumption of other goods, implying that both increase demand for meat products as a group. However, $10 \%$ increases in either beef or poultry advertising reduce demand for other goods by only $0.002 \%$ and $0.006 \%$. 


\section{Conclusions and Implications}

Recent large increases in expenditures on meat advertising by private brands and producer-financed generic promotion programs make determining the effectiveness of meat advertising on meat demand essential. Poultry consumption and poultry advertising increased significantly in the early 1980 s as more highly processed, differentiated poultry products were produced. At the same time, beef and pork consumption stagnated or declined. These developments spurred beef and pork producer associations to develop generic advertising programs with the goal of increasing demand for their respective meat commodities.

This study used a nonlinear Rotterdam model to estimate impacts of brand and generic meat advertising on meat commodity demand. Particular attention was given to modeling impacts of advertising expenditures on substitute goods. Although generic beef and pork advertising are specifically designed to increase demand for their respective meat commodities, the marginal impacts on beef and pork demand are not significantly different from zero. However, the marginal impacts of branded beef, branded pork, and poultry advertising are significantly different from zero for each respective commodity. Branded beef and poultry advertising have increased overall demand for meats as a group. Brand and generic meat product advertising have caused some substitution among meat commodities.

Certainly, as a host of studies have shown, meat demand is influenced by both price and nonprice factors. Results of our study suggest that advertising should be considered in studies of meat demand. Although advertising elasticity estimates are not large, branded advertising effects are significant. Even small elasticities have potentially large aggregate effects in large-volume commodity markets. In addition, effects of advertising on quarterly consumption of meat commodities dissipate quickly. Thus, an effective meat advertising campaign requires continual (quarterly) expenditures.

Although funds obtained from producer checkoff programs are primarily used for promotion, such funds could be used for other purposes. Alternative uses include financing research for new product development and for reducing production and/or marketing costs. Wohlgenant (1993) argued “...producers should prefer a research-induced decrease in production costs to an equivalent promotion-induced increase in retail price and to a decrease in mar- keting costs" (p. 467). In addition, he noted that estimates of the marginal effectiveness of advertising are necessary to estimate the relevant impacts of using checkoff funds for research or promotion. Ultimately, producers would prefer funding promotion over research only if promotion expenditures cause consumer demand to increase by more than decreases in farm production costs caused by an equivalent expenditure on research (Wohlgenant 1993). Our results show that own-advertising elasticities are between seven and ninety times smaller than own-price elasticities. Thus, relative to increases in advertising expenditures, considerably smaller percentage reductions in ownprices are necessary to induce equivalent increases in consumption.

\section{[Received June 1994; final revision received August 1995.]}

\section{References}

Alston, J.M., and J.A. Chalfant. "Consumer Demand Analysis According to GARP." Northeastern J. Agr. Res. Econ. (October 1992):125-39.

Brester, G.W., and M.K. Wohlgenant. "Estimating Interrelated Demands for Meats Using New Measures for Ground and Table Cut Beef." Amer. J. Agr. Econ. 73(November 1991):1182-94.

Brooker, J.R., D.B. Eastwood, and M.D. Gray. "The Impact of Advertising on Consumer Demand for Beef: An Application of Scan Data." J. Food Prod. Mktg. 2(1994):17-35.

Brown, M.G., and J.Y. Lee. "Theoretical Overview of Demand Systems Incorporating Advertising Effects." Commodity Advertising and Promotion. H.W. Kinnucan, S.R. Thompson, and H.S. Chang, eds., pp. 79-100. Ames IA: Iowa State University Press, 1992.

Chalfant, J.A., and J.M. Alston. "Accounting for Changes in Tastes." J. Polit. Econ. 96(1988):391-410.

Christensen, L.R., and M.E. Manser. "Estimating U.S. Consumer Preferences for Meats with a Flexible Utility Function." J. Econometrics 5(January 1977):37-53.

Chyc, K.M., and E.W. Goddard. "Optimal Investment in Generic Advertising and Research: The Case of the Canadian Egg Market." Agribus. 10(March/April 1994):145-66.

Cox, T.L. "A Rotterdam Model Incorporating Advertising Effects: The Case of Canadian Fats and Oils." Commodity Advertising and Promotion. H.W. Kinnucan, S.R. Thompson, and H.S. Chang, eds., pp. 139-64. Ames IA: Iowa State 
University Press, 1992.

Dahlgran, R.A. "Complete Flexibility Systems and the Stationarity of U.S. Meat Demands." $W . J$. Agr. Econ. 2(December 1987):152-63.

Duffy, M.H. "Advertising and Inter-Product Distribution of Demand." Eur. Econ. Rev. 31(July 1987):1051-70.

Eales, J.S., and L.J. Unnevehr. "Simultaneity and Structural Change in U.S. Meat Demand." Amer. J. Agr. Econ. 75(May 1993):259-68.

Forker, O.D., and R.W. Ward. Commodity Advertising: The Economics and Measurement of Generic Programs. New York: Lexington Books, 1993.

Goddard, E.W., and B. Cozzarin. "A Preliminary Look at Advertising Beef, Pork, Chicken, Turkey, Eggs, Milk, Butter, Cheese, and Margarine." Commodity Advertising and Promotion. H.W. Kinnucan, S.R. Thompson, and H.S. Chang, eds., pp. 120-38. Ames IA: Iowa State University Press, 1992.

Green, R.D. "Dynamic Utility Functions for Measuring Advertising Responses." Proceedings of Research on Effectiveness of Agricultural Commodity Promotion, Seminar. Arlington VA: Farm Foundation and U.S. Department of Agriculture.

Green, R.D., H.F. Carman, and K. McManus. "Some Empirical Methods of Estimating Advertising Effects in Demand Systems: An Application to Dried Fruits." W. J. Agr. Econ. 16(July 1991):63-71.

Hoover, S., M. Hayenga, and S.R. Johnson. "Evaluating the Effectiveness of Generic Pork Advertising: The First Fifteen Months." Commodity Advertising and Promotion. H.W. Kinnucan, S.R. Thompson, and H.S. Chang, eds., pp. 235-60. Ames IA: Iowa State University Press, 1992.

Jensen, H.H., and J.R. Schroeter. "Television Advertising and Beef Demand: An Econometric Analysis of 'Split-Cable' Household Panel Scanner Data." Can. J. Agr. Econ. 40(July 1992):271-94.

Kaiser, H.M., O.D. Forker, J. Lenz, and C.H. Sun. "Evaluating Generic Dairy Advertising Impacts on Retail, Wholesale, and Farm Milk Markets." J. Agr. Econ. Res. 44(1992):3-17.

Kinnucan, H.W., S.R. Thompson, and H.S. Chang, eds. Commodity Advertising and Promotion. Ames IA: Iowa State University Press, 1992.

LaFrance, J.T. "When Is Expenditure 'Exogenous' in Separable Demand Models?" W. J. Agr. Econ. 16(July 1991):49-62.

LaFrance, J.T., and W.M. Hanemann. "The Dual Structure of Incomplete Demand Systems." Amer. J. Agr. Econ. 71(May 1989):262-74.

Leading National Advertisers. Class/Brand QTR \$. New York: Leading National Advertisers, Inc., all issues 1970 through 1994.

Lee, J.Y., M.G. Brown, and G.F. Fairchild. "Some
Observations on the Impact of Advertising on Demand." Agribus. 5(November 1989):607-18.

Mountain, D.C. "The Rotterdam Model: An Approximation in Variable Space." Econometrica 56(March 1988):477-84.

Nerlove, M., and F.V. Waugh. "Advertising Without Supply Control: Some Implications of a Study of the Advertising of Oranges." J. Farm Econ. 43(November 1961):813-37.

Pollak, R.A., and T.J. Wales. "Comparisons of the Quadratic Expenditure System and Translog Demand Systems with Alternative Specifications of Demographic Effects." Econometrica 48(April 1980):595-612.

"Demographic Variables in Demand Analysis." Econometrica 49(November 1981):1533-51.

Sasuly, M. "Irving Fisher and Social Science." Econometrica 15(October 1947):255-78.

Theil, H. The System-Wide Approach to Microeconomics. Chicago: University of Chicago Press, 1980.

U.S. Department of Agriculture. Livestock and Meat Situation and Outlook Report. Washington DC, several issues, 1970-94.

U.S. Department of Commerce, Bureau of Economic Analysis. Survey of Current Business. Washington DC, various issues, 1986-94.

U.S. Department of Labor, Bureau of Labor Statistics. CPI Detailed Reports. Washington DC, various issues.

Varian, H. Microeconomic Analysis, 2nd ed. New York: W.W. Norton \& Company, 1984.

Ward, R.W., and B.L. Dixon. "Effectiveness of Fluid Milk Advertising Since the Dairy and Tobacco Adjustment Act of 1983." Amer. J. Agr. Econ. 71(August 1989):730-40.

Ward, R.W., and C. Lambert. "Generic Promotion of Beef: Measuring the Impact of the U.S. Beef Checkoff." J. Agr. Econ. 44(September 1993):456-65.

Waugh, F.V. "Needed Research on the Effectiveness of Farm Product Promotions." J. Farm Econ. 41(May 1959):364-76.

Wohlgenant, M.K. "Distribution of Gains from Research and Promotion in Multi-Stage Production Systems: The Case of the U.S. Beef and Pork Industries." Amer. J. Agr. Econ. 75(August 1993):642-51.

"Effects of the Changing Composition of Beef Consumption on the Elasticities for Beef and Poultry." The Economics of Meat Demand. Rueben C. Buse, ed., pp. 170-86. Madison WI: University of Wisconsin, 1989.

Wohlgenant, M.K., and C.R. Clary. "Development and Measurement of Farm-to-Retail price Linkage for Evaluating Dairy Advertising Effectiveness." J. Agr. Econ. Res. 44(1992):18-27. 